\title{
Changing patterns of sickness absence among healthcare workers in England during the COVID-19 pandemic
}

\section{Rhiannon Edge ${ }^{1}$, Diana A. van der Plaat ${ }^{2}$, Vaughan Parsons ${ }^{3,4}$, David Coggon ${ }^{5}$, Martie van Tongeren ${ }^{6}$, Rupert Muiry ${ }^{3}$, Ira Madan ${ }^{3,4}$, Paul Cullinan ${ }^{2}$}

${ }^{1}$ Lancaster Medical School, Lancaster University, Lancaster, UK

${ }^{2}$ National Heart and Lung Institute (NHLI), Imperial College London, London, UK

${ }^{3}$ Occupational Health Service, Guy's and St Thomas' NHS Foundation Trust, London, UK

${ }^{4}$ Faculty of Life Sciences and Medicine, King's College London, London, UK

${ }^{5}$ MRC Lifecourse Epidemiology Centre, University of Southampton, Southampton, UK

${ }^{6}$ School of Health Sciences, Centre for Occupational and Environmental Health, University of Manchester, Manchester, UK

Address correspondence to: Ira Madan, E-mail: ira.madan@kcl.ac.uk

\begin{abstract}
Background Patterns of sickness absence shed useful light on disease occurrence and illness-related behaviours in working populations.

Methods We analysed prospectively collected, pseudonymized data on 959356 employees who were continuously employed by National Health Service trusts in England from 1 January 2019 to 31 July 2020, comparing the frequency of new sickness absence in 2020 with that at corresponding times in 2019.

Results After exclusion of episodes directly related to COVID-19, the overall incidence of sickness absence during the initial 10 weeks of the pandemic (March-May 2020) was more than 20\% lower than in corresponding weeks of 2019. Trends for specific categories of illness varied substantially, with a fall by $24 \%$ for cancer, but an increase for mental illness. A doubling of new absences for pregnancy-related disorders during May-July of 2020 was limited to women with earlier COVID-19 sickness absence.

Conclusions Various factors will have contributed to the large and divergent changes that were observed. The findings reinforce concerns regarding delays in diagnosis and treatment of cancers and support a need to plan for a large backlog of treatment for many other diseases. Further research should explore the rise in absence for pregnancy-related disorders among women with earlier COVID-19 sickness absence.
\end{abstract}

Keywords COVID-19, healthcare workers, sickness absence

\section{Introduction}

In addition to its impacts on productivity, sickness absence is important as an indicator of patterns of disease and illness-related behaviours in working populations. During the COVID-19 pandemic, healthcare workers have faced a serious threat to their personal safety, in combination with new and heightened occupational demands from a rapidly evolving crisis. Rates of SARS-CoV-2 infection have been higher in healthcare workers than in most other occupations. ${ }^{1-3}$ Workload has increased because of the exceptional number of patients requiring treatment for the disease, and a need to cover for colleagues who were themselves infected, isolating or shielding. In addition, the pandemic has had wider effects on people's activities and access to health services which could further alter patterns of sickness absence (e.g. through postponement of less urgent clinical investigation and treatment).

Before the pandemic, staff employed by the National Health Service (NHS) in England had persistently high, but stable, overall rates of sickness absence. ${ }^{4,5}$ Preliminary analyses have indicated a sudden rise during the early phase of the epidemic nationally (March-April 2020) with

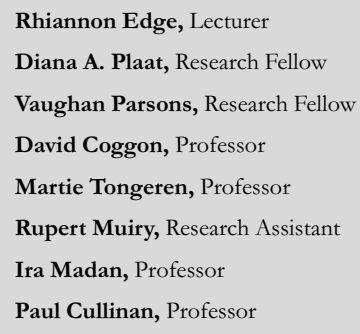


notable variability across geographical areas and between staff groups. ${ }^{6-8}$ Much of this increase will have been driven by absence because of confirmed or suspected COVID-19, but there is a need to examine trends according to different medical reasons for absence.

We report an analysis of data on NHS employees in England, to explore the nature and extent of changes in non-COVID sickness absence during the first wave of the epidemic. We also examine whether absence for COVID19 infection during the early weeks of the epidemic was associated with altered patterns of sickness absence in the longer term.

\section{Methods}

We analysed pseudonymized data that had been abstracted on our behalf from the NHS Electronic Staff Record (ESR). All NHS trusts in England contribute monthly personnel records to the ESR central database, using a standardized coding system. We were given access to information on all staff who had been continuously employed between 1 January 2019 and 31 July 2020. It included demographic and occupational characteristics for each individual, together with data on all absences from work during that period (other than for annual leave), detailing the dates that each episode started and finished, and the reason for absence. An extensive description of the source material and its preliminary processing is presented in an earlier report.?

For the current analysis, we focused on incident episodes of sickness absence across the study sample, classified according to the week of the year in which they started, their duration ( $\leq 7$ days or $>7$ days) and the reason for absence. Reasons for sickness absence were classified to 22 diagnostic categories. In addition, from 17 March 2020, trusts had the option to record whether an absence was related to COVID-19.

Statistical analysis was carried out using $\mathrm{R}$ Statistical Software (version 4.0.4). ${ }^{10}$ We calculated percentage changes (with 95\% confidence intervals (CIs)) from 2019 to 2020 in the numbers of new episodes of sickness absence during corresponding weeks of the year.

The main periods that we examined were chosen to cover the time immediately before the first wave of the COVID-19 epidemic in England took off (weeks 2-10), the time when it was at its height (weeks 11-20) and then a time when it was subsiding (weeks 21-29). The periods of the year studied were specified a priori, and such that public holidays fell in the same period in each year. The data were complete up to 31 July 2020 , and by setting the end of the last period a little earlier, we could reliably determine whether episodes had lasted for longer than 7 days. Year-on-year changes were assessed for all sickness absence, and for sickness absence in which there was no record of COVID-19 as a related reason.

To explore whether infection by COVID-19 was associated with altered patterns of sickness absence in the longer term, we also analysed year-on-year changes for specific categories of absence during weeks 21-29, according to whether individuals had taken COVID-19 sickness absence during weeks 11-18 of 2020. For this purpose, COVID-19 sickness absence was defined as in an earlier report ${ }^{9}$-i.e. sickness absence in any of five diagnostic categories (cough/flu, chest/respiratory, infectious diseases, other, unknown) with COVID-19 recorded as a related reason.

\section{Ethical approval statement}

Ethical approval was provided by the NHS Health Research Authority (reference 20/SC/0282).

\section{Results}

After exclusion of 21775 individuals who were absent continuously throughout the study period, analysis was based on 959356 employees. Most (89\%) were aged between 25 and 60 years, and $77 \%$ were female.

Table 1 shows the numbers of new episodes of sickness absence within the study sample during corresponding 9- or 10 -week periods in 2019 and 2020. Across the three periods in 2020, COVID-19 was recorded as a related reason for absence in a total of 101585 new episodes, of which 100833 (99\%) met our specified criteria for COVID-19 sickness absence. Most (87\%) began during weeks 11-20, and only $414(0.4 \%)$ started earlier in the year.

For sickness absence that was not recorded as COVIDrelated, the overall number of new episodes during weeks 2-10 of 2020 was similar to that in the corresponding weeks of 2019 (274 720 versus 278 006), although within that, there were increases for mental illness (by 28.8\%) and headache/migraine (by 12.8\%), offset by a reduction for cough/flu (by 12.0\%). In contrast, much larger yearon-year changes were observed during weeks 11-20. The total number of new non-COVID absences fell by $21.5 \%$, including reductions for gastrointestinal problems (by 48.4\%), genitourinary/gynaecological disorders (by 33.8\%), eye problems (by 42.7\%), injury and fracture (by $27.7 \%$ ), back problems (by 19.6\%), other musculoskeletal disorders (by $29.3 \%$ ), disorders of ear, nose and throat (by $32.7 \%$ ), cough/flu (by 24.5\%) and cancer (by 24.1\%). On the other hand, large increases were observed for infectious diseases (by $283 \%$ ), asthma (by $122 \%$ ), chest and respiratory disorders 

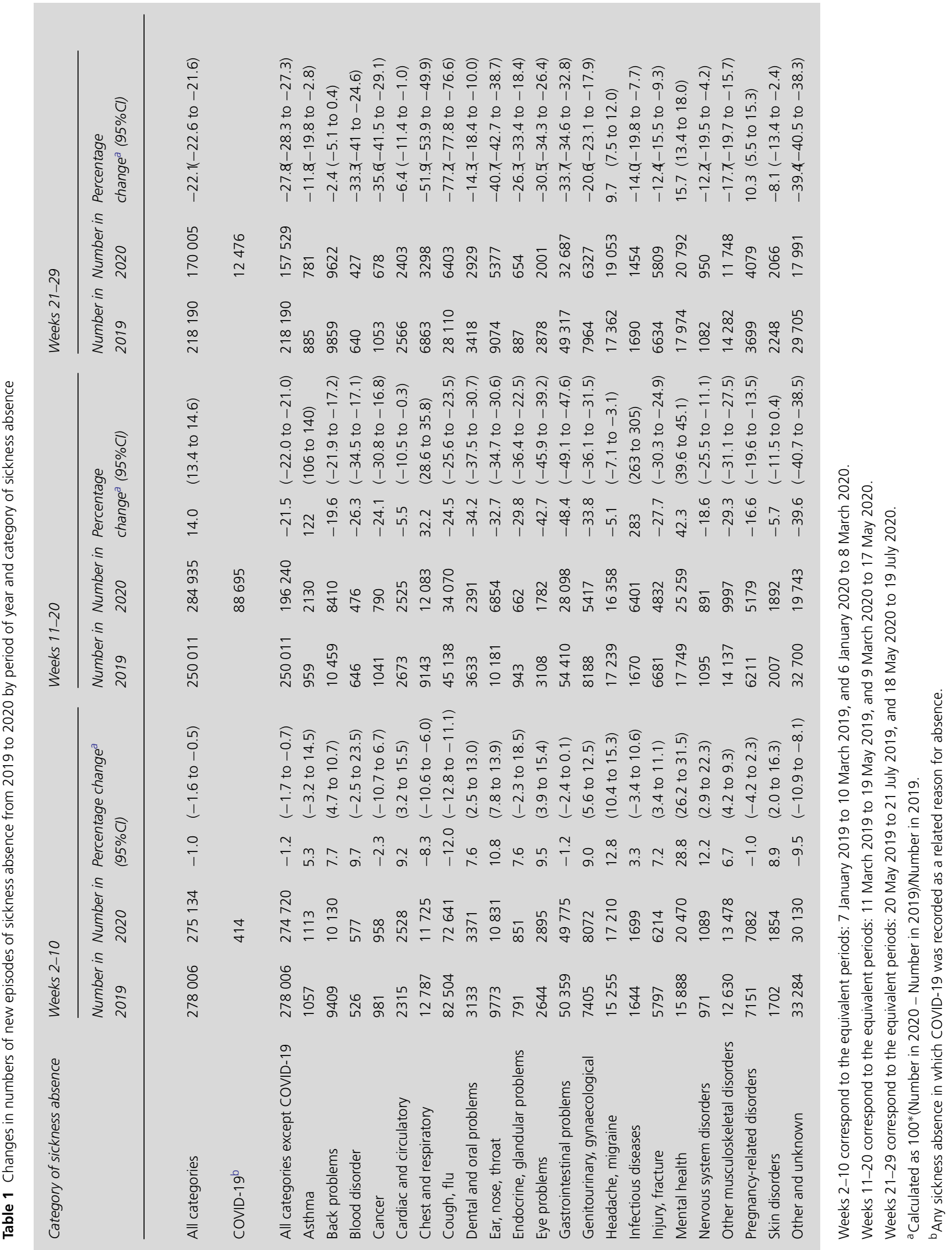


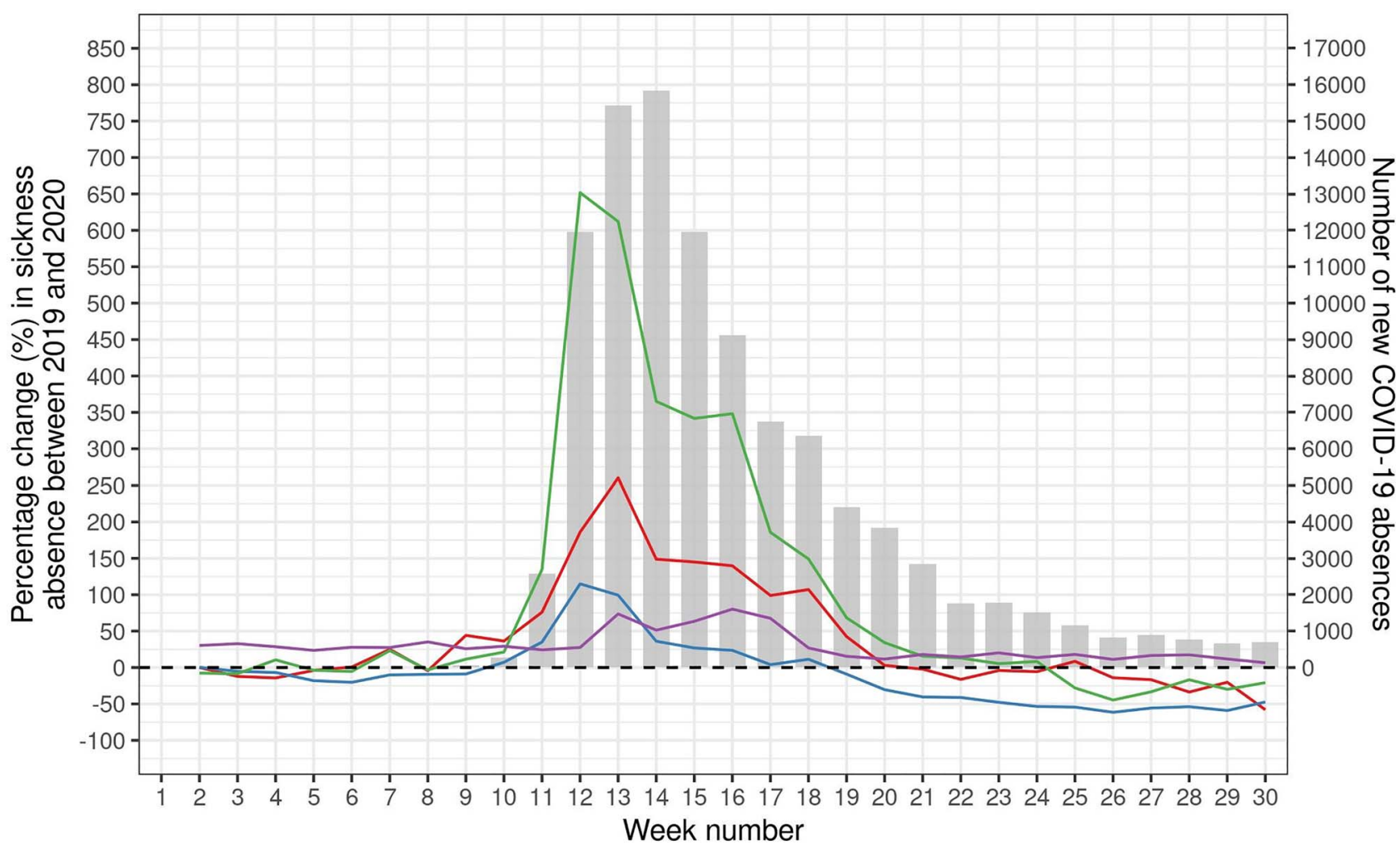

— Asthma — Chest and respiratory — Infectious diseases — Mental health

Fig. 1 Percentage change from 2019 to 2020 in new episodes of sickness absence for selected causes and number of new absences for COVID-19 by week of year.

(by $32.2 \%$ ) and mental illness (by $42.3 \%$ ). In the third period (weeks 21-29), the overall year-on-year reduction in non-COVID absences was maintained (down by $27.8 \%$ ), with changes for most specific diagnostic categories in the same direction as for weeks 11-20. Exceptions, however, were asthma, chest and respiratory disorders and infectious diseases, for all of which numbers were lower in 2020 than in 2019, and pregnancy-related disorders, for which there was a $10 \%$ increase.

Figure 1 shows the percentage change from 2019 to 2020 in new episodes of sickness absence by individual week of the year for selected diagnostic categories, and weekly numbers of new episodes of COVID-19 sickness absence during 2020. The surges in absence for infectious diseases, asthma and chest and respiratory disorders all coincided with the emergence of absences for COVID-19, peaking 1-2 weeks earlier, while the increase in new absences for mental illness was less steep and peaked several weeks later.

Table 2 breaks down the year-on-year changes in numbers of new absence episodes during weeks 11-29 according to whether they were of short ( $\leq 7$ days) or longer duration. The increases for asthma, chest and respiratory disorders, infectious diseases and mental illness were all larger for longer term than for short-duration episodes. There were also increases in long-duration absences for cough/flu and cardiac and circulatory disease, whereas short-duration absences for these diagnostic categories were less frequent in 2020 than in 2019. The reduction in absences for cancer was greater for shortduration episodes (48.1\%) but was apparent also for episodes of longer duration (18.0\%).

Table 3 shows percentage changes from 2019 to 2020 in numbers of new absences during weeks 21-29, according to whether individuals had COVID-19 sickness absence during weeks $11-18$ of 2020 . There were few clear indications (from 95\% confidence intervals) of a differential change in subsequent patterns of new sickness absence following previous absence for COVID-19. However, the year-on-year increase in new absences for pregnancy-related disorders during weeks 21-29 was much greater among women with earlier COVID-19 sickness absence (215\%, 95\%CI 159-284\%) than in those without COVID-19 $(2.8 \%, 95 \% \mathrm{CI}-1.8$ to $7.6 \%$ ). 
Table 2 Changes in numbers of new episodes of sickness absence during weeks 11-29 from 2019 to 2020 by category and duration of sickness absence

\begin{tabular}{|c|c|c|c|c|c|c|c|c|}
\hline \multirow{2}{*}{$\begin{array}{l}\text { Category of sickness } \\
\text { absence }\end{array}$} & \multicolumn{4}{|c|}{ Duration of absence $\leq 7$ days } & \multicolumn{4}{|c|}{ Duration of absence $>7$ days } \\
\hline & $\begin{array}{l}\text { Number in } \\
2019\end{array}$ & $\begin{array}{l}\text { Number in } \\
2020\end{array}$ & $\begin{array}{l}\text { Percent } \\
(95 \% \mathrm{Cl})\end{array}$ & ge change ${ }^{a}$ & $\begin{array}{l}\text { Number in } \\
2019\end{array}$ & $\begin{array}{l}\text { Number in } \\
2020\end{array}$ & $\begin{array}{l}\text { Percent } \\
\text { change }\end{array}$ & $\begin{array}{l}\text { ge } \\
(95 \% \text { Cl) }\end{array}$ \\
\hline All categories & 379770 & 300545 & -20.9 & $(-21.2$ to -20.5$)$ & 88431 & 154395 & 74.6 & (73.2 to 76.0 ) \\
\hline $\begin{array}{l}\text { All categories except } \\
\text { COVID-19 }\end{array}$ & 379770 & 250449 & -34.1 & $(-34.4$ to -33.7$)$ & 88431 & 103320 & 16.8 & (15.8 to 17.9$)$ \\
\hline Asthma & 1471 & 1647 & 12.0 & (4.4 to 20.1$)$ & 373 & 1264 & 239 & (202 to 280 ) \\
\hline Back problems & 14642 & 12080 & -17.5 & $(-19.5$ to -15.5$)$ & 5676 & 5952 & 4.9 & (1.1 to 8.7 ) \\
\hline Blood disorder & 823 & 504 & -38.8 & $(-45.2$ to -31.6$)$ & 463 & 399 & -13.8 & $(-24.6$ to -1.5$)$ \\
\hline Cancer & 825 & 428 & -48.1 & $(-53.8$ to -41.7$)$ & 1269 & 1040 & -18.0 & $(-24.5$ to -11.0$)$ \\
\hline Cardiac and circulatory & 3315 & 2811 & -15.2 & $(-19.4$ to -10.8$)$ & 1924 & 2117 & 10.0 & (3.4 to 17.0 ) \\
\hline Chest and respiratory & 12175 & 8034 & -34.0 & $(-35.8$ to -32.1$)$ & 3831 & 7347 & 91.8 & (84.4 to 99.4 ) \\
\hline Cough, flu & 69177 & 30507 & -55.9 & $(-56.5$ to -55.3$)$ & 4071 & 9966 & 145 & (136 to 154$)$ \\
\hline Dental and oral problems & 6489 & 4862 & -25.1 & $(-27.8$ to -22.2$)$ & 562 & 458 & -18.5 & $(-28.0$ to -7.8$)$ \\
\hline Ear, nose, throat & 16346 & 9840 & -39.8 & $(-41.3$ to -38.3$)$ & 2909 & 2391 & -17.8 & $(-22.1$ to -13.2$)$ \\
\hline $\begin{array}{l}\text { Endocrine, glandular } \\
\text { problems }\end{array}$ & 1212 & 814 & -32.8 & $(-38.5$ to -26.6$)$ & 618 & 502 & -18.8 & $(-27.8$ to -8.6$)$ \\
\hline Eye problems & 4673 & 2998 & -35.8 & $(-38.7$ to -32.8$)$ & 1313 & 785 & -40.2 & $(-45.3$ to -34.7$)$ \\
\hline Gastrointestinal problems & 98113 & 56124 & -42.8 & $(-43.4$ to -42.2$)$ & 5614 & 4661 & -17.0 & $(-20.1$ to -13.7$)$ \\
\hline $\begin{array}{l}\text { Genitourinary, } \\
\text { gynaecological }\end{array}$ & 11977 & 9199 & -23.2 & $(-25.3$ to -21.1$)$ & 4175 & 2545 & -39.0 & $(-42.0$ to -36.0$)$ \\
\hline Headache, migraine & 33292 & 33648 & 1.1 & $(-0.5$ to 2.6$)$ & 1309 & 1763 & 34.7 & (25.4 to 44.7 ) \\
\hline Infectious diseases & 2463 & 4174 & 69.5 & (61.2 to 78.1$)$ & 897 & 3681 & 310 & (281 to 341$)$ \\
\hline Injury, fracture & 7160 & 5643 & -21.2 & $(-23.9$ to -18.4$)$ & 6155 & 4998 & -18.8 & $(-21.8$ to -15.7$)$ \\
\hline Mental health & 14973 & 15768 & 5.3 & (3.0 to 7.7 ) & 20750 & 30283 & 45.9 & (43.4 to 48.5 ) \\
\hline Nervous system disorders & 1424 & 1092 & -23.3 & $(-29.1$ to -17$)$ & 753 & 749 & -0.5 & $(-10.1$ to 10.1$)$ \\
\hline $\begin{array}{l}\text { Other musculoskeletal } \\
\text { disorders }\end{array}$ & 18215 & 13741 & -24.6 & $(-26.2$ to -22.9$)$ & 10204 & 8004 & -21.6 & $(-23.8$ to -19.2$)$ \\
\hline Pregnancy-related disorders & 7110 & 5618 & -21.0 & $(-23.7$ to -18.2$)$ & 2800 & 3640 & 30.0 & (23.8 to 36.6 ) \\
\hline Skin disorders & 3201 & 2762 & -13.7 & $(-18.0$ to -9.2$)$ & 1054 & 1196 & 13.5 & ( 4.5 to 23.3 ) \\
\hline Other and unknown & 50694 & 28155 & -44.5 & $(-45.3$ to -43.6$)$ & 11711 & 9579 & -18.2 & $(-20.4$ to -16$)$ \\
\hline
\end{tabular}

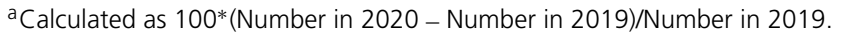

\section{Discussion}

\section{Main findings of this study}

Our analysis confirms that during the first wave of COVID19 in England there were major changes in the incidence of sickness absence among NHS staff as compared with the corresponding period a year earlier. For some diagnostic categories (e.g. asthma, chest and respiratory disease, infectious diseases and mental illness), rates of absence increased (at least initially), whereas for others (e.g. musculoskeletal disorders, injury and fracture, gastrointestinal disease, genitourinary and gynaecological disease and, most notably, cancer), there were substantial reductions. COVID-19 sickness absence during weeks 11-18 of 2020 was not clearly associated with a higher year-on-year rise in new sickness absence during weeks 21-29, other than for pregnancy-related disorders.

The diverging trends that we report may have been driven by various mechanisms including direct effects of COVID19; a lower threshold for absence because of symptoms that might be caused by coronavirus infection; fears about vulnerability to COVID-19 in the presence of some comorbidities; pressures either at work or domestically as a consequence of the epidemic; a higher threshold for taking sickness absence 
in general because of the need to respond to the emergency posed by COVID-19; changes in activities outside work as a consequence of the epidemic; reluctance to present to medical services; health system reprioritization and longer term trends unrelated to COVID-19.

\section{What is already known on this topic}

Patterns of orthopaedic injury observed during the COVID19 epidemic (low-energy/fragility trauma persisted, while injuries associated with younger people reduced) indicate that social distancing measures contributed to the reduction. ${ }^{11}$ Referrals for suspected cancer in the UK during AprilAugust 2020 were down by approximately 350000 compared with the same period in $2019,{ }^{12}$ as a consequence, 40000 fewer patients started cancer treatment in $2020 .{ }^{13}$ Evidence is emerging that COVID-19 poses an increased risk in pregnancy, with higher odds of premature birth than in women who do not have the disease, ${ }^{14}$ and a greater risk of severe illness (particularly in the context of high body mass index and pre-existing comorbidities) as compared with that in infected women of the same age who are not pregnant. ${ }^{15}$

\section{What this study adds}

This is the first large study of the effects of the COVID19 pandemic on sickness absence in healthcare workers for illness not directly attributable to coronavirus infection. The large sample size (almost a million individuals) gave the investigation high statistical power, and because we limited it to staff who were employed continuously throughout the study period, changes in numbers of new absences directly reflected changes in incidence rates. Moreover, they could not be confounded by differences between individuals in propensity to take sickness absence when ill, although they could reflect changes over time in thresholds for taking absence.

Absences for infectious disease and chest and respiratory disorders increased sharply in March 2020 compared with 2019 and closely paralleled the trajectory of COVID-19 sickness absence. This may have reflected failure to correctly identify and label some illness as COVID-related, especially early in the epidemic when testing was less widely available. In addition, individuals may have had a lower threshold for taking absence for illnesses with COVID-like symptoms because of the possibility that it might be caused by coronavirus. Yearon-year increases were predominantly for longer duration absences (Table 2), which suggests that the former was the main driver of the increase.

The pattern of sickness absence attributed to cough/flu was different, with year-on-year reductions in sickness absence episodes throughout the first wave of the epidemic. However, those reductions related only to short-duration episodes, and following the onset of the epidemic, new long-term episodes more than doubled (Table 2). Again, this is likely to reflect failure to identify and label COVID-related illness. The fall in short-term absence may be attributable to reductions in the incidence of common respiratory infections as a consequence of measures taken to reduce transmission of coronavirus. ${ }^{16,17}$

The surge in new absences for asthma closely paralleled the rise in COVID-19 sickness absence (Fig. 1) and was driven by episodes of longer duration (Table 2). It is possible that during the early phase of the epidemic, some workers with asthma took precautionary sickness absence due to concerns about vulnerability to COVID-19 (on which the evidence at that stage was uncertain). ${ }^{18}$

The year-on-year fall in new episodes of absence for injury and fracture, which applied to both short and longer duration absence (Table 2), was more marked in the early phase of the epidemic (Table 1) when restrictions on activities outside work were greatest. It may have resulted, at least in part, from lower rates of injuries because of reductions in activities such as sports and driving.

A year-on-year increase in sickness absence for mental health was apparent prior to the COVID-19 epidemic, but it was most marked in weeks 11-20, suggesting that stresses relating to the epidemic (either at or outside work) may have led to an increase in mental illness. This will be explored in more detail in a separate paper.

New episodes of sickness absence for cardiovascular disease and cancer declined in the 20 weeks following the onset of the COVID-19 epidemic, but the reduction was much greater for cancer $(30 \%)$ than for cardiac and circulatory disorders $(6 \%)$. There is no reason to suspect that the incidence of such diseases changed as a consequence of the pandemic, and the trends are more likely to have been driven by changes in health-seeking behaviour, and the postponement of less urgent investigations (e.g. in follow-up of patients) due to reprioritization of health systems. ${ }^{19}$ There may have been some reluctance to seek medical advice about new symptoms when healthcare services were under pressure, especially where symptoms were not seriously incapacitating. In addition, individuals may have postponed medical consultation because they were preoccupied in adjusting to personal/professional demands posed by the pandemic. The reduction in sickness absence for cancer was greatest for short-duration episodes, indicative of a change in health-seeking behaviour. Whatever the reason, the finding adds to concerns about an impending problem from late diagnosis and treatment of cancers as a consequence of the pandemic. In the case of 
Table 3 Changes from 2019 to 2020 in numbers of new episodes of sickness absence during weeks 21-29 by category of sickness absence, according to whether individuals had new COVID-19 sickness absence during weeks 11-18 of 2020

\begin{tabular}{|c|c|c|c|c|c|c|c|c|}
\hline \multirow[t]{2}{*}{$\begin{array}{l}\text { Category of sickness } \\
\text { absence }\end{array}$} & \multicolumn{4}{|c|}{$\begin{array}{l}\text { No new COVID-19 sickness absence during weeks } \\
11-18 \text { of } 2020\end{array}$} & \multicolumn{4}{|c|}{$\begin{array}{l}\text { New COVID-19 sickness absence during weeks } \\
11-18 \text { of } 2020\end{array}$} \\
\hline & $\begin{array}{l}\text { Number in } \\
2019\end{array}$ & $\begin{array}{l}\text { Number in } \\
2020\end{array}$ & $\begin{array}{l}\text { Percent } \\
(95 \% \mathrm{Cl}\end{array}$ & ge change ${ }^{a}$ & $\begin{array}{l}\text { Number in } \\
2019\end{array}$ & $\begin{array}{l}\text { Number in } \\
2020\end{array}$ & Percent & ge change $(95 \%$ Cl) \\
\hline All categories & 195563 & 151106 & -22.7 & $(-23.2$ to -22.2$)$ & 22627 & 18899 & -16.5 & $(-18.1$ to -14.8$)$ \\
\hline $\begin{array}{l}\text { All categories except } \\
\text { COVID-19 }\end{array}$ & 195563 & 140839 & -28.0 & $(-28.5$ to -27.5$)$ & 22627 & 16690 & -26.2 & $(-27.7$ to -24.7$)$ \\
\hline Asthma & 791 & 685 & -13.4 & $(-21.8$ to -4.1$)$ & 94 & 96 & 2.1 & $(-23.2$ to 35.7$)$ \\
\hline Back problems & 8798 & 8605 & -2.2 & $(-5.1$ to 0.8$)$ & 1061 & 1017 & -4.1 & $(-12.0$ to 4.5$)$ \\
\hline Blood disorder & 574 & 378 & -34.1 & $(-42.2$ to -25$)$ & 66 & 49 & -25.8 & $(-48.7$ to 7.4$)$ \\
\hline Cancer & 990 & 620 & -37.4 & $(-43.4$ to -30.8$)$ & 63 & 58 & -7.9 & $(-35.6$ to 31.5$)$ \\
\hline Cardiac and circulatory & 2279 & 2114 & -7.2 & $(-12.6$ to -1.6$)$ & 287 & 289 & 0.7 & $(-14.5$ to 18.6$)$ \\
\hline Chest and respiratory & 6183 & 2836 & -54.1 & $(-56.1$ to -52.0$)$ & 680 & 462 & -32.1 & $(-39.6$ to -23.5$)$ \\
\hline Cough, flu & 25165 & 5766 & -77.1 & $(-77.7$ to -76.4$)$ & 2945 & 637 & -78.4 & $(-80.1$ to -76.4$)$ \\
\hline Dental and oral problems & 3059 & 2600 & -15.0 & $(-19.3$ to -10.4$)$ & 359 & 329 & -8.4 & $(-21.1$ to 6.4$)$ \\
\hline Ear, nose, throat & 8111 & 4858 & -40.1 & $(-42.2$ to -37.9$)$ & 963 & 519 & -46.1 & $(-51.6$ to -40.0$)$ \\
\hline $\begin{array}{l}\text { Endocrine, glandular } \\
\text { problems }\end{array}$ & 799 & 564 & -29.4 & $(-36.6$ to -21.4$)$ & 88 & 90 & 2.3 & $(-23.8$ to 37.2$)$ \\
\hline Eye problems & 2578 & 1814 & -29.6 & $(-33.7$ to -25.3$)$ & 300 & 187 & -37.7 & $(-48.1$ to -25.2$)$ \\
\hline Gastrointestinal problems & 44211 & 29352 & -33.6 & $(-34.6$ to -32.6$)$ & 5106 & 3335 & -34.7 & $(-37.5$ to -31.8$)$ \\
\hline $\begin{array}{l}\text { Genitourinary, } \\
\text { gynaecological }\end{array}$ & 7103 & 5656 & -20.4 & $(-23.1$ to -17.5$)$ & 861 & 671 & -22.1 & $(-29.5$ to -13.8$)$ \\
\hline Headache, migraine & 15617 & 17038 & 9.1 & (6.8 to 11.5$)$ & 1745 & 2015 & 15.5 & (8.3 to 23.1 ) \\
\hline Infectious diseases & 1505 & 1313 & -12.8 & $(-19.0$ to -6.1$)$ & 185 & 141 & -23.8 & $(-38.8$ to -5.1$)$ \\
\hline Injury, fracture & 5922 & 5212 & -12.0 & $(-15.2$ to -8.7$)$ & 712 & 597 & -16.2 & $(-24.8$ to -6.5$)$ \\
\hline Mental health & 16126 & 18673 & 15.8 & (13.4 to 18.3 ) & 1848 & 2119 & 14.7 & (7.7 to 22.0$)$ \\
\hline Nervous system disorders & 974 & 843 & -13.4 & $(-21.1$ to -5.1$)$ & 108 & 107 & -0.9 & $(-24.2$ to 29.4$)$ \\
\hline $\begin{array}{l}\text { Other musculoskeletal } \\
\text { disorders }\end{array}$ & 12639 & 10492 & -17.0 & $(-19.1$ to -14.8$)$ & 1643 & 1256 & -23.6 & $(-29.0$ to -17.7$)$ \\
\hline Pregnancy-related disorders & 3569 & 3669 & 2.8 & $(-1.8$ to 7.6$)$ & 130 & 410 & 215 & (159 to 28 ) \\
\hline Skin disorders & 2051 & 1845 & -10.0 & $(-15.5$ to -4.2$)$ & 197 & 221 & 12.2 & $(-7.4$ to 35.9$)$ \\
\hline Other and unknown & 26519 & 15906 & -40.0 & $(-41.2$ to -38.8$)$ & 3186 & 2085 & -34.6 & $(-38.1$ to -30.8$)$ \\
\hline
\end{tabular}

${ }^{a}$ Calculated as 100*(Number in 2020 - Number in 2019)/Number in 2019.

cardiovascular disease, the impact of delayed diagnosis and treatment may be more immediate than for cancer, and that could explain why the incidence of longer duration absence for cardiac and circulatory disorders rose despite a fall in short-duration absences (Table 3).

A combination of factors could have contributed to declines following the onset of the epidemic in absence for categories of illness such as dental and oral problems; disorders of ear, nose and throat; endocrine and glandular disease; eye problems; genitourinary and gynaecological disorders; diseases of the nervous system and skin problems.
They include altered thresholds for taking absence for minor symptoms because of a wish to support patients and colleagues when services are stretched; diversion of resources from other services (e.g. less urgent surgery) to the management of COVID-19; and avoidance of healthcare settings because of a perceived risk of exposure to infection. ${ }^{20}$ The last two could again be expected to forebode long-term challenges from a backlog of untreated morbidity.

Pregnancy-related disorders were the only category of sickness absence for which the year-on-year increase was 
greatest in weeks 21-29, and remarkably, that increase was limited to women who had an earlier episode of COVID19 sickness absence during weeks 11-18 (Table 3). This cannot be explained by women opting for earlier maternity leave, which was coded separately from sickness absence, nor is it likely to reflect generic fears about risks from COVID-19 during pregnancy - the rise occurred after the initial peak of the epidemic and did not follow the pattern observed for asthma. Moreover, it was limited to women with earlier COVID-19 sickness absence. While that is an imperfect measure of COVID-19 infection, we have shown previously that it correlated with a positive antibody test for SARS-CoV-2.

\section{Limitations of this study}

Information in the central ESR database had been collected prospectively through monthly updates, which were provided by NHS trusts in a standardized format. Dates of absence should have been highly reliable, but reasons for absence, which will have been determined originally from a combination of self-report and (for longer episodes) medical certification, may have been more prone to error, and also to inconsistencies in coding. In general, however, we would not expect there to have been systematic changes in the misclassification of reasons for sickness absence over the study period.

The broad categories that were used when coding reasons for absence should have reduced the scope for misclassification, but they prevented us from exploring patterns of absence in finer detail. Nor was it possible to investigate longer-term trends, although the year-on-year comparison for the weeks 2-10 provided some insight into levels of change that might have been expected in the absence of COVID-19.

\section{Conclusions}

The COVID-19 pandemic has had a profound effect on patterns of sickness absence among NHS staff. Of particular concern is the marked reduction in sickness absence for cancer, which suggests an added burden of future morbidity, and perhaps mortality, as a consequence of delays in diagnosis and treatment-such effects would be expected to extend to the wider population. In addition, plans are needed to manage a backlog of treatment for many other categories of disease that has been postponed because of the COVID-19 pandemic. Further research should be undertaken to understand the rise in absence for pregnancy-related disorders, which was limited to women with earlier COVID-19 sickness absence.

\section{Data availability}

With permission, source data are available upon request from the NHS Electronic Staff Record (ESR) Warehouse (NHS England).

\section{Contributorship statement}

All authors contributed to the planning, conduct, analyses and reporting of this manuscript as outlined below.

Rhiannon Edge (Lecturer in Population Health) was responsible for advising on study design, analysis and interpretation of results.

Diana van der Plaat (Statistician) was responsible for the statistical aspects of analysis and interpretation of the quantitative aspects of the study.

Vaughan Parsons (Research manager) was responsible for overseeing the set-up and delivery of the study and facilitated data collection.

David Coggon (Emeritus Professor of Occupational and Environmental Medicine) was responsible for advising on methodological design, analysis and interpretation of results.

Martie van Tongeren (Professor of Occupational and Environmental Medicine) was responsible for advising on study design, analysis and interpretation of results.

Rupert Muiry (Research assistant) was responsible for scoping out and reviewing the emerging literature.

Ira Madan (Consultant Occupational Physician and Reader) was co-chief investigator with responsibility for advising on study design, analysis and interpretation of results.

Paul Cullinan (Professor in Occupational and Environmental Respiratory Disease) was chief investigator with responsibility for advising on study design, analysis and interpretation of results. He had overall responsibility for the management and delivery of the study.

\section{Acknowledgements}

We are very grateful to the following, without whom the study would not have been possible: Sam Wright, Workforce Information Advisor, NHS Electronic Staff Record, and Mike Vickerman, Workforce Information and Analysis, DHSC. Dr Gavin Debrera (Public Health England) and Dr Kit Harling gave invaluable help in planning the study. We are grateful too, to Lee Isidore, Manal Sadik and Victoria Thorpe for their helpful input into the interpretation of our findings.

\section{Funding}

This work was supported by Colt Foundation UK, award number not applicable. 


\section{Conflict of interest}

All authors have completed the ICMJE uniform disclosure form at www.icmje.org/coi_disclosure.pdf and declare: no support from any organization for the submitted work; no financial relationships with any organizations that might have an interest in the submitted work in the previous 3 years; no other relationships or activities that could appear to have influenced the submitted work.

\section{References}

1 ONS. Coronavirus (COVID-19) Infection Survey Pilot: 5 June 2020, Office for National Statistics. 2020. https://www.ons.gov.uk/ peoplepopulationandcommunity/healthandsocialcare/condition sanddiseases/bulletins/coronaviruscovid19infectionsurveypilot/ 5 june2020.

2 ONS. Coronavirus (COVID-19) Related Deaths by Occupation, England and Wales (March-December 2020), Office for National Statistics. 2021. https://www.ons.gov.uk/peoplepopulationandcommunity/ healthandsocialcare/causesofdeath/bulletins/coronaviruscovid19 relateddeathsbyoccupationenglandandwales/deathsregistered between 9 marchand 28 december 2020 .

3 Riley S, Ainslie KEC, Eales $\mathrm{O}$ et al. Community prevalence of SARSCoV-2 virus in England during May 2020: REACT study. medRxiv 2020. https://doi.org/10.1101/2020.07.10.20150524.

4 Chartered Institute of Personnel Development (CIPD). Absence Management 2013 -. Survey Report. London: CIPD; 2013. https://www.cipd.co.uk/knowledge/fundamentals/relations/absence/ absence-management-surveys\#gref

5 Gohar B, Larivière M, Nowrouzi-Kia B. Sickness absence in healthcare workers during the COVID-19 pandemic. Occupational Medicine. 2020;70(5):338-42.

6 Appleby J. NHS sickness absence during the covid-19 pandemic. BMJ. 2021;372:n471.

7 Khorasanee R, Grundy T, Isted A, Breeze R. The Effects of COVID19 on Sickness of Medical Staff across Departments: a Single Centre Experience. London, England: Clinical Medicine, 2021.

8 Zheng C, Hafezi-Bakhtiari N, Cooper V et al. Characteristics and transmission dynamics of COVID-19 in healthcare workers at a
London teaching hospital. The Journal of Hospital Infection. 2020;106(2): 325-329.

9 Van der Plaat D, Madan I, Coggon D et al. Occupational risks of COVID-19 in NHS workers in England. In press at Occupational and Environment Medicine. 2021.

$10 \mathrm{R}$ Core Team. $R$ : A Language and Environment for Statistical Computing. Vienna, Austria: R Foundation for Statistical Computing, 2020.

11 Murphy T, Akehurst H, Mutimer J. Impact of the 2020 COVID19 pandemic on the workload of the orthopaedic service in a busy UK district general hospital. Injury. 2020;51(10): $2142-7$.

12 The Lancet Oncology. UK cancer care threatened by government incompetence. The Lancet Oncology 2020;21(11):1387.

13 Cancer Research UK. Cancer Services during COVID-19: 40,000 Fewer People Starting Treatment. UK: Cancer Research UK, 2021.

14 Allotey J, Stallings E, Bonet M et al. Clinical manifestations, risk factors, and maternal and perinatal outcomes of coronavirus disease 2019 in pregnancy: living systematic review and meta-analysis. BMJ. 2020;370:m3320.

15 RCOG. Coronavirus infection and pregnancy. Information for pregnant women and their families. Royal College of Obstetrician o Gynaecologists 2021. https://www.rcog.org.uk/en/guidelinesresearch-services/guidelines/coronavirus-pregnancy/covid-19virus-infection-and-pregnancy/\#pregnancy.

16 Jones N. How coronavirus lockdowns stopped flu in its tracks. Nature. 2020. doi: 10.1038/d41586-020-01538-8.

17 Karlsson EA, Mook PAN, Vandemaele K, et al. Review of global influenza circulation, late 2019 to 2020, and the impact of the COVID19 pandemic on influenza circulation. World Health Organisation. Weekly Epidemiological Record NO 25, 2021;241-264.

18 Wang Y, Ao G, Qi X, Xie B. The association between COVID-19 and asthma: a systematic review and meta-analysis. Clinical and Experimental Allergy 2020;50(11):1274-7.

19 Lai AG, Pasea L, Banerjee A et al. Estimated impact of the COVID19 pandemic on cancer services and excess 1 -year mortality in people with cancer and multimorbidity: near real-time data on cancer care, cancer deaths and a population-based cohort study. BMJ Open. 2020;10(11):e043828.

20 Daniels S, Wei H, Han Y et al. Risk factors associated with respiratory infectious disease-related presenteeism: a rapid review. medRxiv 2021. 